Article

\title{
Ring-Core Photonic Crystal Fiber of Terahertz Orbital Angular Momentum Modes with Excellence Guiding Properties in Optical Fiber Communication
}

\author{
Fahad Ahmed Al-Zahrani ${ }^{1, *(\mathbb{D})}$ and Md. Anowar Kabir ${ }^{2}$ (D) \\ 1 Computer Engineering Department, Umm Al-Qura University, Mecca 24381, Saudi Arabia \\ 2 Department of Information and Communication Technology, Mawlana Bhashani Science and Technology \\ University, Santosh, Tangail 1902, Bangladesh; anowarkabir.mbstu@gmail.com \\ * Correspondence: fayzahrani@uqu.edu.sa
}

check for updates

Citation: Al-Zahrani, F.A.;

Kabir, M.A. Ring-Core Photonic Crystal Fiber of Terahertz Orbital Angular Momentum Modes with Excellence Guiding Properties in Optical Fiber Communication.

Photonics 2021, 8, 122.

https://doi.org/10.3390/

photonics 8040122

Received: 15 February 2021

Accepted: 23 March 2021

Published: 14 April 2021

Publisher's Note: MDPI stays neutral with regard to jurisdictional claims in published maps and institutional affiliations.

Copyright: (c) 2021 by the authors. Licensee MDPI, Basel, Switzerland. This article is an open access article distributed under the terms and conditions of the Creative Commons Attribution (CC BY) license (https:/ / creativecommons.org/licenses/by/ $4.0 /)$.

\begin{abstract}
The orbital angular momentum (OAM) of light is used for increasing the optical communication capacity in the mode division multiplexing (MDM) technique. A novel and simple structure of ring-core photonic crystal fiber (RC-PCF) is proposed in this paper. The ring core is doped by the Schott sulfur difluoride material and the cladding region is composed of fused silica with one layer of well-patterned air-holes. The guiding of Terahertz (THz) OAM beams with 58 OAM modes over $0.70 \mathrm{THz}(0.20 \mathrm{THz}-0.90 \mathrm{THz})$ frequency is supported by this proposed RC-PCF. The OAM modes are well-separated for their large refractive index difference above $10^{-4}$. The dispersion profile of each mode is varied in the range of $0.23-7.77 \mathrm{ps} / \mathrm{THz} / \mathrm{cm}$. The ultra-low confinement loss around $10^{-9} \mathrm{~dB} / \mathrm{cm}$ and better mode purity up to 0.932 is achieved by this RC-PCF. For these good properties, the proposed fiber is a promising candidate to be applied in the THz OAM transmission systems with high feasibility and high capacity.
\end{abstract}

Keywords: orbital angular momentum (OAM); mode division multiplexing (MDM); space division multiplexing (SDM); ring-core photonic crystal fiber (RC-PCF); optical communication; mode separation; terahertz $(\mathrm{THz})$

\section{Introduction}

Increasing the receptivity of optical fiber transmission links is an exigent task due to the swiftly growing necessity for information transmission capacity. For achieving communication capacity, the physical wave of the light beam-the frequency, wavelength, amplitude, phase, and polarization - has been used to convey information. This is done by using multiplexing techniques, such as polarization division multiplexing (PDM), wavelength division multiplexing (WDM), mode-division multiplexing (MDM), space division multiplexing (SDM) and some advanced modulation techniques [1-3]. The SDM exploits an unrecognized physical dimension space domain. This is the most plight, feasible, and effective way to enhance the capacity of the optical fiber link [4]. The orbital angular momentum (OAM) is one of the techniques of SDM, which has become a significant topic and also increases the applications field of optical communication [5,6], imaging [7], micromanipulation [8], and quantum data technology [9,10]. Normally, OAM beams are linked with a helical front of $e^{(i l \phi)}$, where $l$ is an integer number named the topological charge, and $\phi$ is the azimuthal angle. At present, OAM beams are generated by converting the Laguerre Gaussian beams [11], spiral plates [12], cylindrical lenses [13], and diffracted optical elements $[14,15]$. Nevertheless, by increasing the transmission distance, the OAM beams are slowly expanded in free space, which is exaggerated to their field of applications. Normally, step-index fibers [16,17], twisted fibers [18], grade index ring-based fibers [19], and fiber couplers [20] have been used to carry OAM states.

Nowadays, Terahertz (THz) systems are better for security inspection observation, imaging, and short-range ultra-bandwidth communication. The $\mathrm{THz}$ radiation is located 
between the microwave and infrared frequency, around 0.10 to $10 \mathrm{THz}$ [21]. The OAM beams have scintillating, significant, and intriguing applications like optical microscopy, tweezing, and high-capacity optical transmission [22]. Recently, THz OAM has been a flourishing research topic concentrating on the spatial $\mathrm{THz}$ circulation generation [23-26]. It was found that doughnut-like OAM states are not very easy to start with the THz beams, which are linearly polarized from the $\mathrm{THz}$ source because of mode mismatch. Nonetheless, until now, the propagation of THz OAM is rarely analyzed and discussed but it has a great potential for a robust and stable $\mathrm{THz}$ transmission system depending on the OAM multiplexing technique.

For increasing the massive growth of information capacity, a huge number of OAM supported PCFs have been numerically analyzed and proposed at the optical communication waveband around $1550 \mathrm{~nm}$ [27]. The OAM supported optical fiber with a high indexed material doped ring is very advantageous because the OAM beams and the wave propagating region are doughnut-shaped [16]. Moreover, all solid step-indexed $\mathrm{THz}$-supported PCFs are more challenging because the main problem is lacking transparent materials for the $\mathrm{THz}$ wave-guides. For the range of the $\mathrm{THz}$ spectrum, dry air is a more transparent and available medium. Many hollow-core $\mathrm{THz}$ wave demonstrators have been proposed, analyzed, and experimentally investigated such as all-dielectric wave-guides [28], metal-wire embedded dielectric wave-guides [29], and dielectric coated metallic wave-guides [30]. The most familiar guiding technique among these is the antiresonant reflecting optical waveguide (ARROW) with a leaky behavior. The operating frequencies of ARROW with extreme loss regions are controlled through the thickness and refractive indices of the high indexed layer [31], whereas anti-resonant frequency sections are used for achieving low loss circulation. The ARROW technique with a hollow-core $\mathrm{THz}$ wave-guide is one of the best approaches to achieve a relatively low loss at the $\mathrm{THz}$ regime [32-34]. In 2016, J. Yang et al. [35] proposed and designed a hollow core Kagome PCF for THz wave-guide with a propagation loss of $0.002 \mathrm{~cm}^{-1}$ at $0.75 \mathrm{THz}$. In the same year, M. R. Hasan et al. [36] designed and analyzed a porous-core spiral PCF with confinement loss $10^{-3} \mathrm{~dB} / \mathrm{cm}$ for $\mathrm{THz}$ wave guidance. Besides, OAM transmission with a large number of OAM states, low confinement loss, smooth dispersion variation, and better OAM quality are also considered. For developing those parameters of the PCF, some unique types of PCFs have been proposed and discussed before, such as the spiral PCF [37], circular PCF [38], chain PCF [39], quasi-crystal fiber [40], ring-based PCFs [41-44], and so forth. The ring-based material doped PCF is one of them for better quality and properties with efficient OAM transmission with fabrication possibilities. In 2019, H. Zhang et al. [41] designed a ring-core-based Erbium-doped circular PCF supporting 14 OAM modes. In 2020, M. F. Israk et al. [42] proposed, designed, and investigated a Schott sulfur Di-fluoride $\left(S_{2}\right)$ doped ring based coil-shaped circular PCF supporting 56 OAM states with ultra-low confinement loss $\left(1.7407 \times 10^{-9} \mathrm{~dB} / \mathrm{cm}\right)$ and smooth dispersion variation. Besides, $\mathrm{S}$. H. Huang et al. [43] also designed a micro-structured high-indexed material doped (Schott $\mathrm{SF}_{2}$ and phosphate glass) ring-based PCF with low confinement loss and a minimum dispersion variation of $2.92416 \mathrm{ps} / \mathrm{nm} / \mathrm{km}$ at $H E_{31,1}$ mode. They also discussed the fabrication possibilities of high indexed ring based fiber and enabled support of 146 and 70 OAM modes for different materials. In addition, few of the essential parameters of optical communication are also discussed in that work. Recently, W. Wang et al. [44] proposed a dual guided Schott $S F_{6}$ doped ring-core based PCF with Schott LLF1 (very light flint) background material supporting 56 OAM modes and 4 LP modes with low crosstalk and confinement loss lower than $5 \times 10^{-8} \mathrm{~dB} / \mathrm{m}$. Moreover, the THz-based OAM transmission is has rarely been discussed. In 2016, H. Li et al. [21] proposed a hollow core Kagome $\mathrm{PCF}$ for guiding $\mathrm{THz}$ OAM beams by following the ARROW-type $\mathrm{THz}$ waveguide. They analyzed the fiber characteristics over $0.20 \mathrm{THz}$ to $0.90 \mathrm{THz}$ for 2 groups of OAM modes with a confinement loss of around $10^{-3} \mathrm{~dB} / \mathrm{cm}$ and OAM purity values beyond 0.90 . A tabular and descriptive view is shown in Table 1 for some $\mathrm{THz}$ guiding and material doped ring-core OAM fibers based on PCF structures. So, from the above discussion, it can be 
said that we need to devise a new type of fiber for supporting THz OAM transmission with more performance analyses.

Table 1. THz guiding and material doped ring-core orbital angular momentum (OAM) fibers based on photonic crystal fiber (PCF) structures.

\begin{tabular}{ccccccc}
\hline Year & Author & Lattice & Material & $\begin{array}{c}\text { Number of } \\
\text { OAM Modes }\end{array}$ & $\begin{array}{c}\text { Operating } \\
\text { Bandwidth }\end{array}$ & Reference \\
\hline 2016 & H. Li et al. & Kagome & Polymer & 3 & $700 \mathrm{GHz}$ & {$[21]$} \\
2019 & H. Zhang et al. & Circular & Erbium & 14 & $560 \mathrm{~nm}$ \\
2020 & M. F. Israk et al. & Coil & Schott $S F_{2}$ & 56 & $1900 \mathrm{~nm}$ & {$[41]$} \\
2019 & S. H. Huang et al. & Circular & Schott $S F_{2} \&$ phosphate glass & 146 and 70 & $900 \mathrm{~nm}$ & {$[42]$} \\
2020 & W. Wang et al. & Circular & Schott $S F_{6}$ & $56+4$ & $300 \mathrm{~nm}$ & {$[44]$} \\
\hline
\end{tabular}

In this paper, we designed a light-guiding Schott $S F_{2}$ doped ring-based photonic crystal fiber for supporting Terahertz orbital angular momentum over a wide frequency range of $0.20-0.90 \mathrm{THz}$. The proposed circular PCF supported 58 OAM states. The PCF design and algorithm of the proposed PCF are represented in Section 2. The simulation results and discussion of the parameters are given in Section 3. The fabrication possibilities of the proposed PCF are discussed in Section 4. Finally, the conclusion is briefly summarized in Section 5.

\section{PCF Design and Algorithm}

Combining the benefits of the $\mathrm{THz}$ wave guidance and OAM transmission, we have designed a circular ring-core PCF (RC-PCF), supporting a large number of OAM modes, ultra-low confinement loss, flat dispersion, and better OAM quality in a broad $\mathrm{THz}$ frequency range. The cross-section of the proposed RC-PCF and the corresponding physical notation with description is shown in Figure 1a,b, respectively, with a list of size parameters, where $r_{0}$ and $r_{1}$ are the inner and outer radii of the light-guiding ring-core, respectively, and $t_{1}$ and $t_{2}$ are the thickness of the ring-core and perfectly matched layer (PML), respectively. The $\wedge d$ are the pitch distance of air holes and the diameter of the air hole, respectively, and the ratio between them is the relative air diameter $(d / \wedge)$. The PML is used outside the computation domain. The thickness of the PML $t_{2}$ is around $9 \%$ of the whole radius of the cross-section of the fiber. The $\rho$ is named as the ratio of the circular radii of ring-core and expressed through $r_{0} / r_{1}$. By changing this ratio, the number of the supported OAM modes and the quality of the OAM modes are varied. This ratio is used for measuring and comparing the OAM purity for different vector modes that are discussed later. The PCF is composed of a ring-core and a well-ordered layer of an air hole. The light-guiding and mode beam-bearing ring are doped through a high indexed material of Schott $\mathrm{SF}_{2}$ with refractive index 1.62 [44] at $1550 \mathrm{~nm}$ wavelength. This high indexed ring-core contributes to the well-separated eigenmodes, although there are various types of glass material like LASF and SF11 for doping the light guiding path. But, for the high refractive index and relatively rough dispersion, these are not used for doping. On the other hand, $S F_{2}$ is better for dispersion and internal transmission, which was proved in References [42,43]. Besides, the background material of the proposed RC-PCF is fused silica with a relatively lower refractive index than Schott $\mathrm{SF}_{2}$ of 1.446 [45]. The air holes outside the ring-core distribute the refractive index through the whole section of the fiber, which is favorable for tuning the wave-guide dispersion [46]. Since the THz OAM is a new concept of multiplexing system OAM in optical communication, so the structure of a fiber can be simple. 

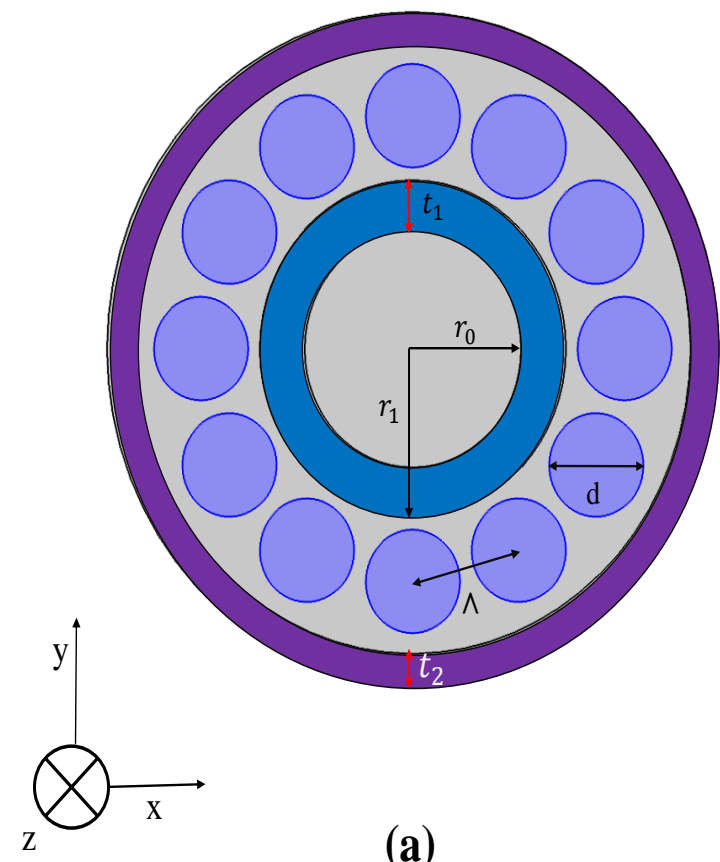

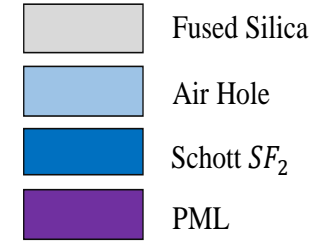

\begin{tabular}{l|l}
\multicolumn{1}{c|}{ Parameter } & \multicolumn{1}{c}{ Description } \\
\hline$r_{0}=450 \mu \mathrm{m}$ & Inner radius of the ring-core \\
\hline$r_{1}=635 \mu \mathrm{m}$ & Outer radius of the ring-core \\
\hline$\rho\left(r_{0} / r_{1}\right)=0.71$ & Ratio of annular radii of ring-core \\
\hline$t_{1}=185 \mu \mathrm{m}$ & Thickness of the ring-core \\
\hline$t_{2}=110 \mu \mathrm{m}$ & Thickness of the PML \\
\hline $\mathrm{d}=365 \mu \mathrm{m}$ & Diameter of the air-hole \\
$\Lambda=440 \mu \mathrm{m}$ & Pitch of air-hole \\
\hline $\mathrm{d} / \Lambda=0.83$ & Relative air-hole diameter
\end{tabular}

(b)

Figure 1. (a) Cross-section of the proposed ring-core PCF (b) Necessary description and size of the structural parameters.

The proposed RC-PCF is designed and simulated through the COMSOL Multiphysics cross-platform software. For all the simulation results, except OAM purity, the values of the ratio of annular radii of ring-core and relative air diameter are fixed and these are $\rho=0.71$ and $\mathrm{d} / \wedge=0.83$. For increasing the number of OAM modes, the radius of the inner diameter $\left(r_{0}\right)$ of the proposed fiber is fixed at $0.45 \mathrm{~mm}$. The simulation of the proposed PCF is done by the full-vector finite element method (FEM). The FEM and PML are used to calculate effective refractive indices for vector modes and electromagnetic mode field distributions. There are many methods for calculating the numerical values of PCF such as the plane wave, the supercell lattice method, the finite difference time domain method, and so forth. Nonetheless, FEM is a method for solving a partial differential equation with high precision. It also can combine multiple disciplines, such as mechanics, chemistry, acoustics, and optics. There are widespread application fields of FEM such as vehicle design, ship design and architectural structure. The effective refractive index, ring-core and total wave guiding power are calculated through the FEM method for the proposed PCF. The key steps are as follows-modeling the PCF geometry and doping material, select the values of $\rho$ and $\mathrm{d} / \wedge$ considering the support of OAM transmission in the $\mathrm{THz}$ range frequency, select the operating frequency band, set the definitions and electromagnetic boundary conditions, pattern analysis, grid division, and setting expressions for derived values of global evaluations.

A large number of OAM modes ensure high capacity and secure data transmission. The OAM has become a robust multiplexing technique because of a huge number of OAM modes. For the proposed fiber, the supported OAM modes are expressed as $O A M_{ \pm l, m}^{ \pm}$ and they can be presented through $H E_{l+1, m}$ and $E H_{l-1, m}$. All the supported OAM and eigenmodes are mathematically expressed through the following Equations (1) and (2) [42].

$$
\begin{gathered}
\left\{\begin{array}{l}
O A M_{ \pm l, m}^{ \pm}=H E_{l+1, m}^{\text {even }} \pm j H E_{l+1, m}^{o d d} \\
O A M_{ \pm l, m}^{ \pm}=E H_{l-1, m}^{\text {even }} \pm j E H_{l-1, m}^{o d d}
\end{array}\right\} ;(l>1), \\
\left\{\begin{array}{c}
O A M_{ \pm l, m}^{ \pm}=H E_{2, m}^{\text {even }} \pm j H E_{2, m}^{\text {odd }} \\
O A M_{ \pm l, m}^{\mp}=T M_{0, m}^{+} \pm j T E_{0, m}
\end{array}\right\} ;(l=1) .
\end{gathered}
$$


Here, the superscript ' \pm ' is denoted as the polarization direction of spin angular momentum. From the above formulas, it can be seen that the rotation direction of HE modes with the direction of spin angular momentum, while the EH modes follow the opposite rotation direction $[47,48]$. Besides, even and odd modes are obtained after the $\pi / 2$ phase shift and ' $\pm \mathrm{l}^{\prime}$ ' denotes the rotation direction of the wavefront. The radial orders with $m>1$ are not considered because of their disturbance in multiplexing and demultiplexing of OAM modes [44], thus we considered only m equal to 1. By following Equations (1) and (2), the $58 \mathrm{OAM}$ and eigenmodes are supported through the proposed RC-PCF over the whole supported frequency band. These are $-O A M_{ \pm 1,1}^{ \pm}\left(H E_{2,1}\right), O A M_{ \pm 2,1}^{ \pm}\left(H E_{3,1}, E H_{1,1}\right), O A M_{ \pm 3,1}^{ \pm}$ $\left(H E_{4,1}, E H_{2,1}\right), O A M_{ \pm 4,1}^{ \pm}\left(H E_{5,1}, E H_{3,1}\right), O A M_{ \pm 5,1}^{ \pm}\left(H E_{6,1}, E H_{4,1}\right), O A M_{ \pm 6,1}^{ \pm}\left(H E_{7,1}, E H_{5,1}\right)$, $O A M_{ \pm 7,1}^{ \pm}\left(H E_{8,1}, E H_{6,1}\right), O A M_{ \pm 8,1}^{ \pm}\left(H E_{9,1}, E H_{7,1}\right), O A M_{ \pm 9,1}^{ \pm}\left(H E_{10,1}, E H_{8,1}\right), O A M_{ \pm 10,1}^{ \pm}$ $\left(H E_{11,1}, E H_{9,1}\right), O A M_{ \pm 11,1}^{ \pm}\left(H E_{12,1}, E H_{10,1}\right), O A M_{ \pm 12,1}^{ \pm}\left(H E_{13,1}, E H_{11,1}\right), O A M_{ \pm 13,1}^{ \pm}\left(H E_{14,1}\right.$, $\left.E H_{12,1}\right), O A M_{ \pm 14,1}^{ \pm}\left(H E_{15,1}, E H_{13,1}\right), O A M_{ \pm 15,1}^{ \pm}\left(H E_{16,1}, E H_{14,1}\right)$.

All the supported OAM modes show a well limited intensity and phase distribution in the annular region. A well-structured mode field distribution is better for the OAM multiplexing technique. The intensity distribution of $H E_{1,1}, E H_{4,1}, H E_{9,1}, H E_{12,1}, H E_{16,1}$, $T M_{0,1}, T E_{0,1}$, and phase distributions of $H E_{4,1}, E H_{5,1}, H E_{10,1}$ are presented in Figure 2.

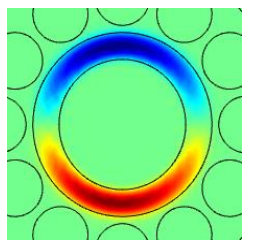

(a) $H E_{1,1}$

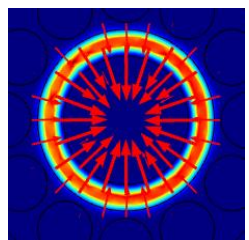

(f) $T M_{0,1}$

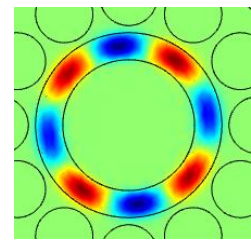

(b) $E H_{4,1}$

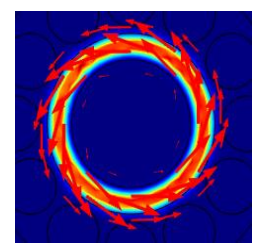

(g) $T E_{0,1}$

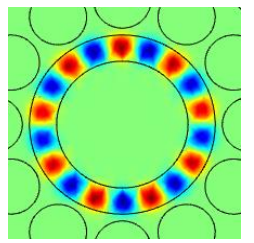

(c) $H E_{9,1}$

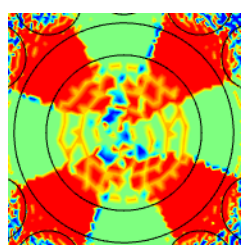

(h) $H E_{4,1}$

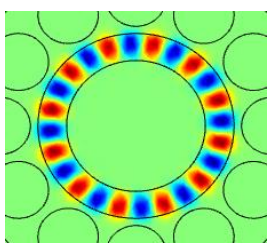

(d) $H E_{12,1}$

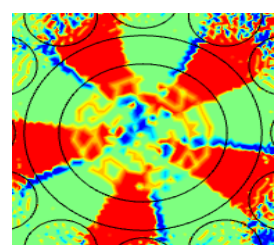

(i) $E H_{5,1}$

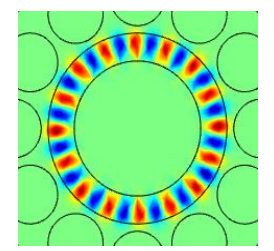

(e) $E H_{16,1}$

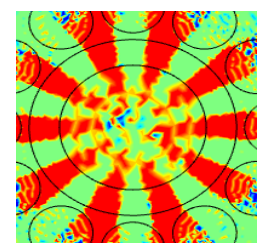

(j) $H E_{10,1}$

Figure 2. (a-g) intensity distributions of $H E_{1,1}, E H_{4,1}, H E_{9,1}, H E_{12,1}, H E_{16,1}, T M_{0,1}, T E_{0,1}$ and (h-j) phase distributions of $H E_{4,1}, E H_{5,1}, H E_{10,1}$.

For enhancing the performance of the proposed PCF, we have discussed and analyzed some significant parameters of THz OAM transmission in a wide frequency band over $0.20 \mathrm{THz}$ to $0.90 \mathrm{THz}$. The effective refractive index (ERI), effective refractive index difference (ERID), dispersion profile, confinement loss (CL) and OAM purity are numerically discussed and analyzed in this paper. The ERID of a group of OAM modes is always greater than $10^{-4}$. It is denoted through $\Delta n_{\text {eff }}$ and calculated by Equation (3) $[48,49]$.

$$
\Delta n_{e f f}=\left|n_{e f f_{H E} E_{l+m}}-n_{e f f_{E H_{l-1, m}}}\right|>10^{-4} .
$$

The dispersion profile in the frequency domain is denoted by $\beta_{2}$ and evaluated through Equation (4) [50].

$$
D=\frac{2}{c} \frac{d n_{e f f}}{d \omega}+\frac{\omega}{c} \frac{d^{2}\left[n_{e f f}\right]}{d \omega^{2}}[p s / T H z / c m] .
$$

Here, $\omega$ is the radian frequency and the $\mathrm{ps} / \mathrm{THz} / \mathrm{cm}$ is the unit of dispersion measurement. The calculation of the CL is done by Equation (5) [51].

$$
C L=\frac{4 \pi f}{c} \operatorname{Im}\left(n_{e f f}\right)(d B / m)=4.187 \times 10^{4} \times \operatorname{Im}\left(n_{e f f}\right)(\mathrm{dB} / \mathrm{cm}) .
$$


Here, $f$ and $c$ are the operating frequency and speed of light in a vacuum. The $\operatorname{Im}\left(n_{e f f}\right)$ is a very small value, which is the imaginary part of the refractive index. The OAM purity of the proposed RC-PCF is calculated through Equation (6) [42].

$$
\eta=\frac{I_{r}}{I_{c}}=\frac{\iint_{\text {rings }}|\vec{E}|^{2} d x d y}{\iint_{\text {cross-section }}|\vec{E}|^{2} d x d y} .
$$

Here, $I_{r}$ is the normal mode of the ring area and $I_{c}$ is the intensity of the average mode in the total cross-view of the proposed PCF.

\section{Simulation Results and Discussions}

By following the previously discussed algorithm, the proposed ring-core fiber is simulated. The simulation results show a significant optical performance with supporting 58 OAM modes, good separation between eigenmodes, smooth dispersion profile, ultra-low confinement loss and better OAM quality. The properties of THz OAM transmission, like effective refractive index, effective refractive index difference, dispersion profile, confinement loss and OAM purity, are calculated, discussed and analyzed with necessary curves and applications. The THz OAM guiding fiber is large in structure, so the effective refractive area is high. Thus, the related parameters of the effective area are neglected in the simulation results and calculations section.

\subsection{Effective Refractive Index}

By following Equations (1) and (2), the effective refractive index of every OAM eigenmode is equivalent to the corresponding even and odd vector modes and these are dependent on the operating frequency. To evaluate the modal effective refractive index $\left(n_{e} f f\right)$ of the proposed fiber, numerical simulations and calculations are done by the finite element solver, where a PML is accomplished adjacent to the cladding. The eigenmodes of $T E_{0,1}, T M_{0,1}$ and all of the supported HE modes are shown in Figure 3, besides all of the EH modes are shown in Figure 4. From both figures, the higher order of OAM modes is clearly represented, showing a lower refractive index, and by increasing the operating frequency, the refractive index is increased. It is known that resonant frequency is ascertained by the optical and geometrical characteristics of the first high-index layer. For guiding the THz OAM transmissions, in Reference [21], two resonant frequencies $(0.45 \mathrm{THz}$ and $0.88 \mathrm{THz}$ ) are used and analyzed as well as some OAM parameters within a certain frequency of $0.20 \mathrm{THz}$ to $0.90 \mathrm{THz}$. In this proposed PCF, the refractive index of all the supported modes is calculated over ranges from $0.20 \mathrm{THz}$ to $0.90 \mathrm{THz}$. The refractive index of all vector modes is between the cladding refractive index (1.446) and the light guiding refractive index (1.62). The dispersion characteristics (in Figure 6) are calculated by using the refractive index.

\subsection{Effective Refractive Index Difference}

Figure 5 shows the relationship between refractive index differences among all of the supported OAM groups and terahertz frequency. By using Equations (1) and (2), the groups are determined at the same topological charge of 1 . The difference is calculated through Equation (3) and the difference must be above $10^{-4}$. The large difference of OAM modes is confirmed, and that adjacent vector modes cannott couple with linear polarization (LP) over the supported frequency band. From Figure 5, it is noticed that the effective refractive index differences are gently decreased by increasing terahertz frequency and a higher-order group of OAM modes shows a higher value of differences. Most of the groups show a difference above $10^{-3}$ and some of them show $10^{-2}$ at $200 \mathrm{GHz}$ and $300 \mathrm{GHz}$. Thus, the proposed PCF is reduced to the crosstalk threshold. The highest effective refractive index difference of $1.7606 \times 10^{-2}$ is gained at $200 \mathrm{GHz}$ frequency for $\left|H E_{16,1}-E H_{14,1}\right|$. This effective performance is obtained for the proposed well-designed PCF structure. So, it can be said that the proposed RC-PCF not only decreased the eigenmodes coupling with 
LP modes but also sustained the transmission with a single mode in the radial direction. For PCF guiding of OAM modes, large effective refractive index difference $\left(\Delta n_{e f f}\right)$ between near-degenerate eigenmodes (normally $>10^{-4}$ ) is highly suitable for long-haul optical transmissions [27].

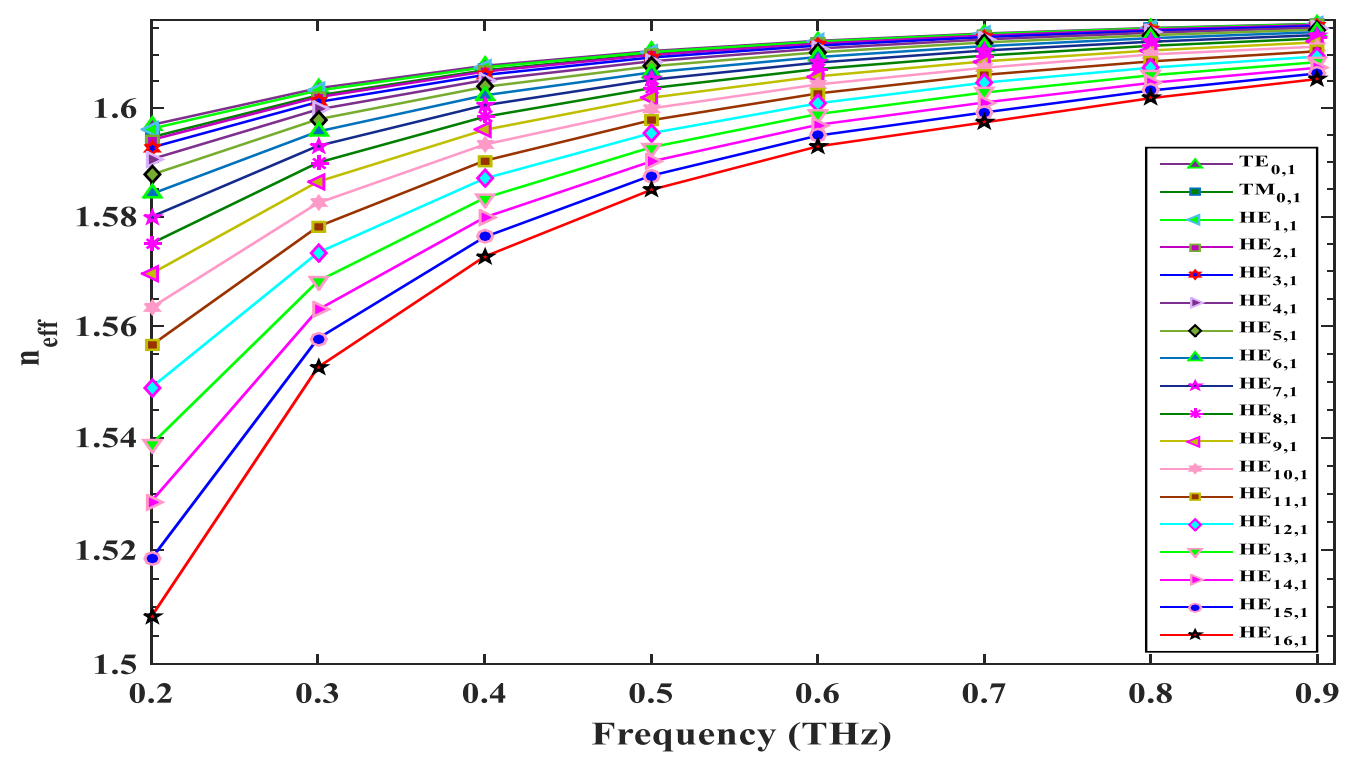

Figure 3. Effective refractive index (ERA) of $T E_{0,1}, T M_{0,1}$ and $\mathrm{HE}$ modes with respect to operating frequency ranging from $0.20 \mathrm{THz}$ to $0.90 \mathrm{THz}$.

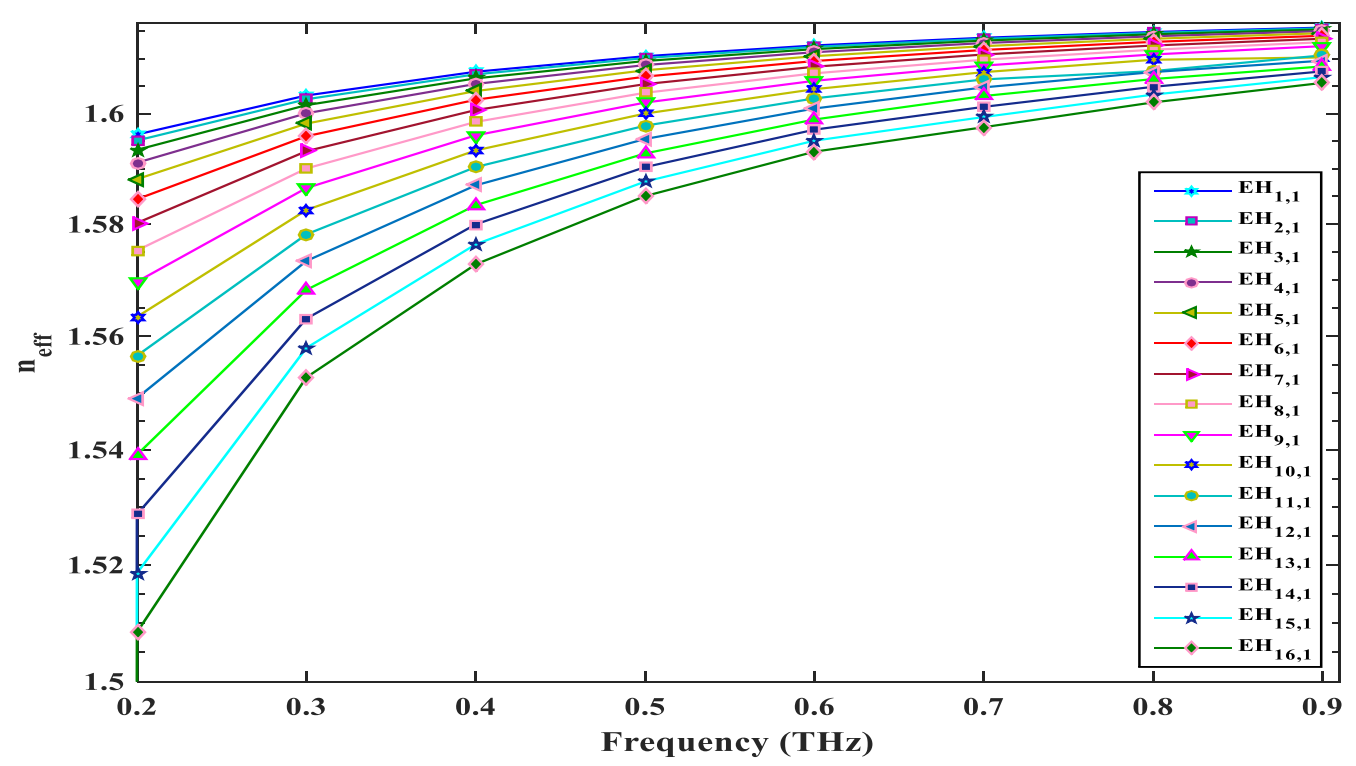

Figure 4. Effective refractive index (ERA) of EH modes with respect to operating frequency ranging from $0.20 \mathrm{THz}$ to $0.90 \mathrm{THz}$. 


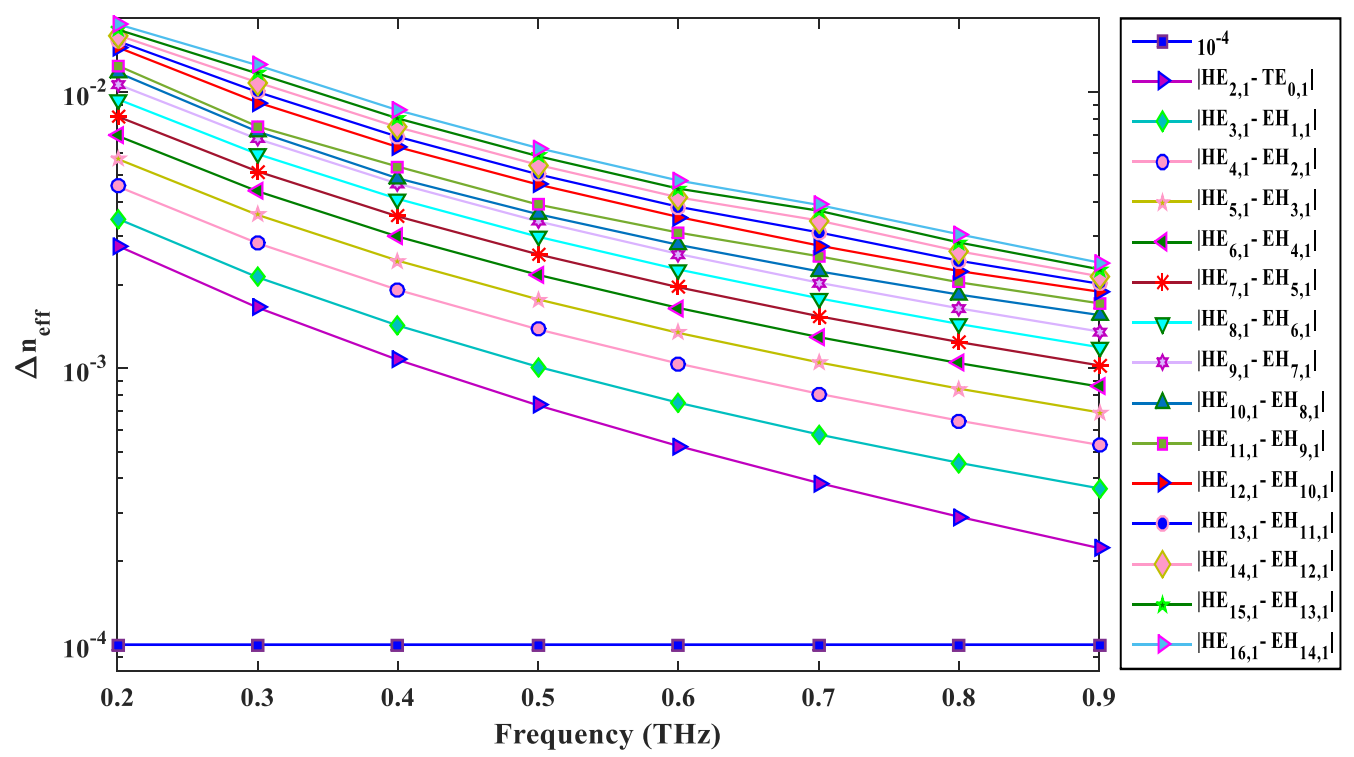

Figure 5. Effective refractive index difference for the same group of OAM modes with respect to operating frequency ranging from $0.20 \mathrm{THz}$ to $0.90 \mathrm{THz}$.

\subsection{Dispersion}

Dispersion is an important property for $\mathrm{THz}$ OAM transmissions. It plays an important role to determine the transmission distance in optical fiber communication systems. It befell for the outpouring of light beams at the time of light propagation through fiber. Normally, there are two types of dispersion including material dispersion and waveguide dispersion. Material dispersion is not discussed here, because it is fixed and dependent on the material which is used for fiber design. On the other hand, the waveguide dispersion can be varied by changing operating wavelength or frequency. It is also adjusted by changing the shape of air holes, the spacing of air holes, the number of air holes, and the arrangements of air holes. For the proposed RC-PCF, we have calculated the dispersion by following Equation (4). Then, the evaluated values are plotted in Figure 6 over a broad range of operating frequencies of about $0.20 \mathrm{THz}$ to $0.70 \mathrm{THz}$. In Equation (4), the dispersion is calculated by differentiating the refractive index in the second order with respect to frequency. The dispersion for the last two operating frequencies $(0.80 \mathrm{THz}$ and $0.90 \mathrm{THz})$ is neglected for its second-order derivation.

From Figure 6, it can be said that dispersion properties are softly decreased by increasing operating frequency and the lower order of OAM modes shows lower dispersion. The dispersion profile (Figure 6) shows an inverse characteristic with an effective refractive index (Figures 3 and 4). The dispersion for all of the eigenmodes is varied from $0.23 \mathrm{ps} / \mathrm{THz} / \mathrm{cm}$ to $7.77 \mathrm{ps} / \mathrm{THz} / \mathrm{cm}$. Dispersion variation is another important parameter for optical communication. It is calculated by determining the absolute difference between two end values of dispersion in the supported operating frequency. Maximum vector modes show a flattened dispersion profile. Besides, the lower dispersion variation is gained for the flattened dispersion. Some lower dispersion variations of $0.8881 \mathrm{ps} / \mathrm{THz} / \mathrm{cm}$, $0.9354 \mathrm{ps} / \mathrm{THz} / \mathrm{cm}, 1.0049 \mathrm{ps} / \mathrm{THz} / \mathrm{cm}, 1.0885 \mathrm{ps} / \mathrm{THz} / \mathrm{cm}, 1.1735 \mathrm{ps} / \mathrm{THz} / \mathrm{cm}$ are obtained for $T E_{0,1}, E H_{1,1}, E H_{2,1}, H E_{2,1}, H E_{3,1}$ modes. A comparative view for dispersion variation for this PCF and some prior PCFs are shown in Table 2. The lower order of the vector modes obtained a lower dispersion variation because lower modes are confined to the light smoothly and outpoured the light slightly for the proposed RC-PCF. In Reference [43], the dispersion variation is greater than this proposed work although this work is investigated under the frequency domain. The RC-PCF is used in the multichannel communication link for its flattened dispersion profile. If the fiber shows a flattened dispersion profile, then multiple signals from the source reached the destination approximately simultaneously [50]. 


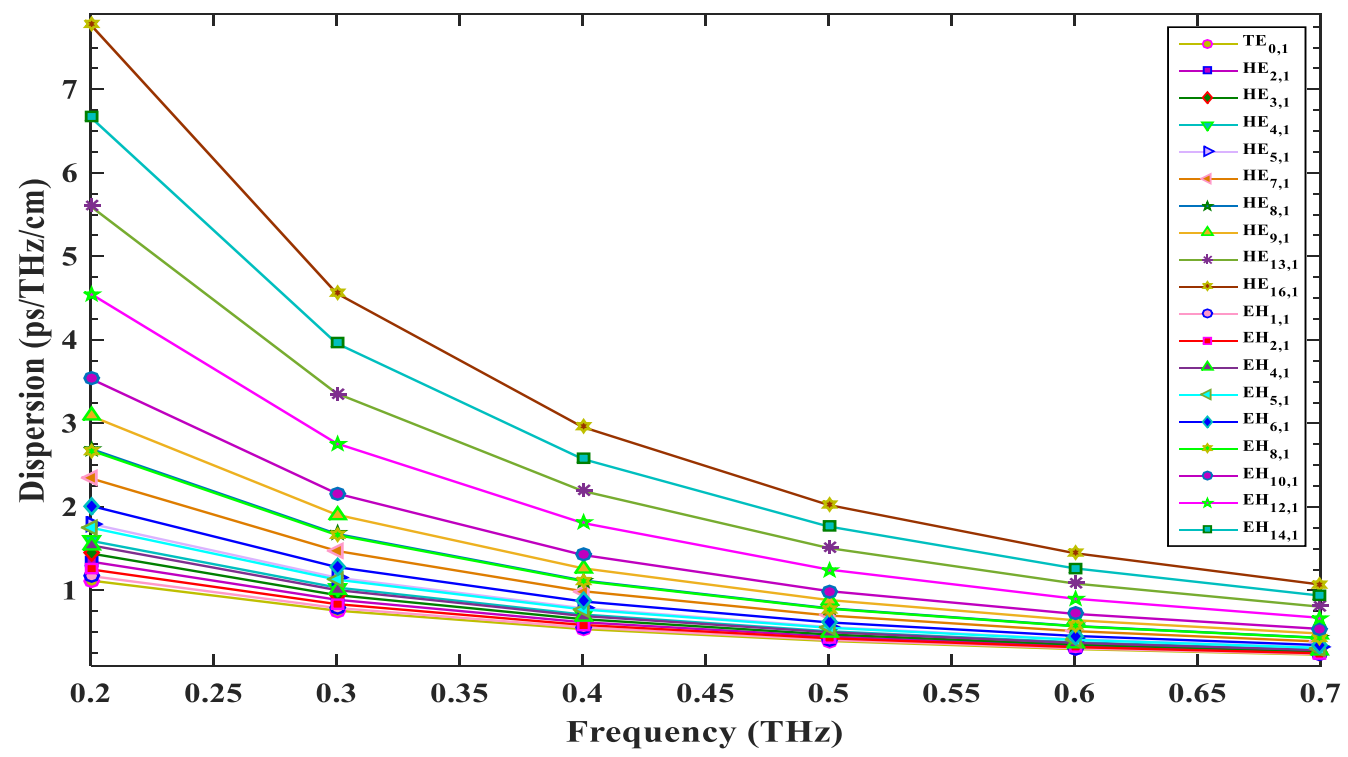

Figure 6. Dispersion for some supported vector modes with respect to operating frequency for the proposed RC-PCF.

Table 2. Comparison of some THz OAM parameters of the operating bandwidth range, supported OAM modes, the lowest confinement loss, and the lowest dispersion variation for the proposed PCF with some prior PCFs.

\begin{tabular}{ccccc}
\hline Reference & Operating Bandwidth Range & Supported OAM Modes & $\begin{array}{c}\text { The Lowest Confinement } \\
\text { Loss (dB/cm) }\end{array}$ & $\begin{array}{c}\text { The Lowest Dispersion } \\
\text { Variation }\end{array}$ \\
\hline$[21]$ & $0.20-0.90 \mathrm{THz}$ & 3 & $\approx 10^{-3}$ & - \\
{$[37]$} & $1.30-2.00 \mu \mathrm{m}$ & 14 & $5.095 \times 10^{-1}$ & $10.35 \mathrm{ps} / \mathrm{km} / \mathrm{nm}$ \\
{$[38]$} & $1.25-2.00 \mu \mathrm{m}$ & 26 & $9.52 \times 10^{-7}$ & - \\
{$[39]$} & $1.20-1.95 \mu \mathrm{m}$ & 56 & $3.19 \times 10^{-8}$ & $3.8684 \mathrm{ps} / \mathrm{km} / \mathrm{nm}$ \\
{$[42]$} & $0.60-2.50 \mu \mathrm{m}$ & 146 & $1.74 \times 10^{-9}$ & $36.907 \mathrm{ps} / \mathrm{km} / \mathrm{nm}$ \\
{$[43]$} & $1.10-2.00 \mu \mathrm{m}$ & 30 & $-10^{-10}$ & - \\
{$[44]$} & $1.52-1.58 \mu \mathrm{m}$ & 42 & $1.131 \times 10^{-8}$ & $-32 \mathrm{ps} / \mathrm{km} / \mathrm{nm}$ \\
{$[48]$} & $0.80-2.00 \mu \mathrm{m}$ & 14 & $3.91 \times 10^{-6}$ & - \\
{$[52]$} & $1.40-1.70 \mu \mathrm{m}$ & 26 & $3.434 \times 10^{-7}$ & $<.7980 \mathrm{ps} / \mathrm{km} / \mathrm{nm}$ \\
{$[53]$} & $1.25-1.81 \mu \mathrm{m}$ & 38 & $1.030 \times 10^{-8}$ & $-4.36 .38 \mathrm{ps} / \mathrm{km} / \mathrm{nm}$ \\
{$[54]$} & $0.80-1.80 \mu \mathrm{m}$ & 58 & $1.534 \times 10^{-7}$ & $0.916 \mathrm{ps} / \mathrm{km} / \mathrm{nm} / \mathrm{nm}$ \\
\hline [55] & $1.00-2.00 \mu \mathrm{m}$ & & $6.91 \times 10^{-9}$ & $0.8881 \mathrm{ps} / \mathrm{THz} / \mathrm{cm}$ \\
\hline This work & $0.20-0.90 \mathrm{THz}$ & &
\end{tabular}

\subsection{Confinement Loss}

Confinement is the light restricting capability at the core of the PCF. Confinement loss (CL) has occurred for the structural imperfections of the fiber structure. Then it is incited through the interior components of the beam [48]. It is a harmful parameter for optical fiber communication. So, we need it to be as low as possible. For the well-structured PCF and the well-patterned air holes layer, the CL became very low. The CL was evaluated through Equation (5). The calculation of the CL is dependent on the unreal part of the effective refractive index, which is very low for the proposed PCF. It is also dependent on the size of the air holes, layers of the air holes, operating frequency, and the guiding mechanism of the fiber. The calculated values of $C L$ for some of the vector modes of $H E_{1,1}, H E_{2,1}, E H_{5,1}$, $H E_{7,1}, E H_{10,1}, H E_{13,1}, H E_{16,1}$ are shown in Figure 7 with respect to operating frequency, ranging from $200 \mathrm{GHz}$ to $900 \mathrm{GHz}$. 


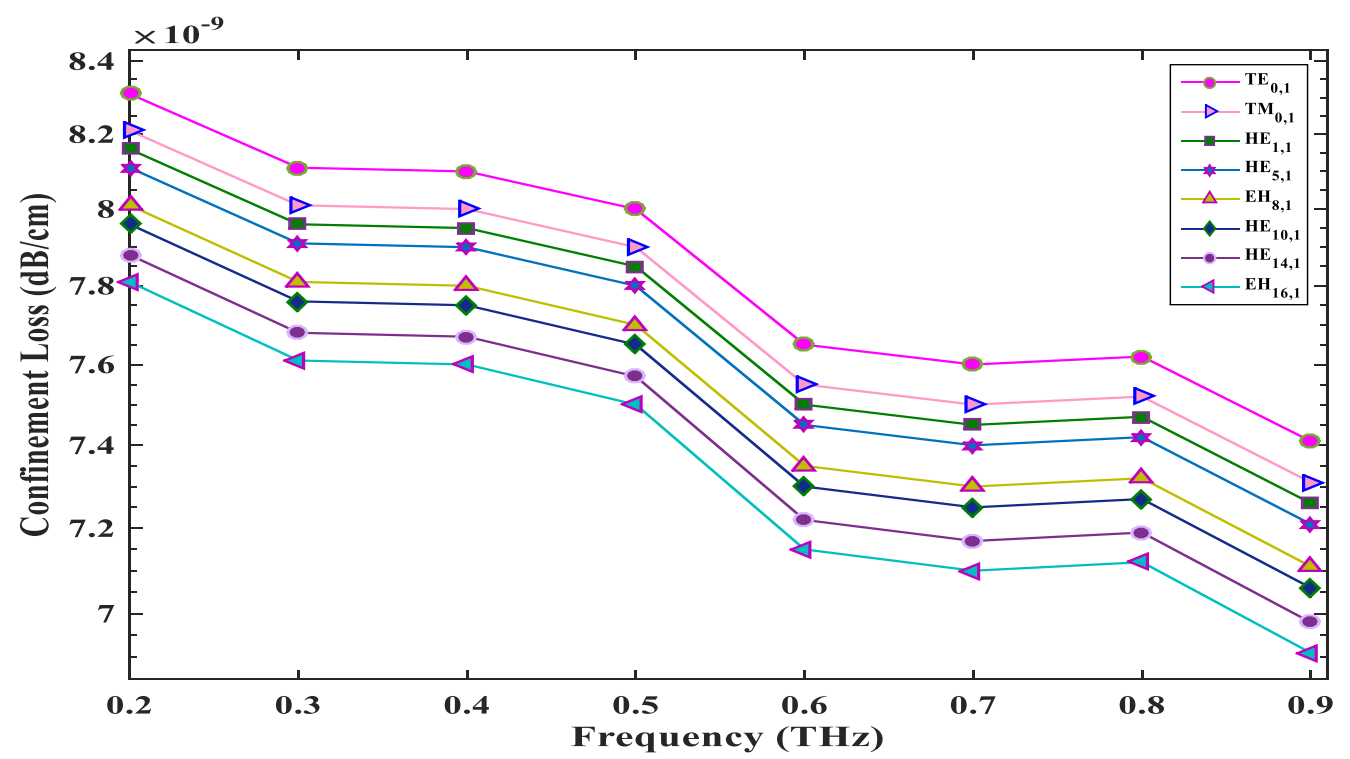

Figure 7. Confinement Loss for some vector modes with respect to operating frequency ranging from $0.20 \mathrm{THz}$ to $0.90 \mathrm{THz}$.

From Figure 7, it is indisputably shown demonstrated that CL for all modes is between $6.91 \times 10^{-9} \mathrm{~dB} / \mathrm{cm}$ to $8.21 \times 10^{-9} \mathrm{~dB} / \mathrm{cm}$. The average $\mathrm{CL}$ of the proposed fiber is comparatively lower than the similarly designed fiber in Reference [43]. These ultra-low values of CL for the proposed PCF are attained for the high indexed material doped mode beam-bearing ring-core and well-patterned large air cavities. The lowest values of CL are obtained for the $H E_{1,1}$ mode. The robust transmission of optical communication and OAM transmission is ensured by this type of relatively lower confinement loss. A comparative view for dispersion variation, confinement loss, supported OAM modes for this PCF and some prior PCFs are shown in Table 2.

\subsection{OAM Purity}

OAM purity is one of the most important parameters for OAM transmissions. The OAM mode purity relates to how light beams are confined in the ring core of the fiber. When a fiber is supported by more numbers of OAM modes, then we should get attention on the purity or quality of OAM modes of this fiber because the high purity of modes ensures the stable transmission of fiber [38]. Mode quality depends on the number of vector modes, the width of ring core, pattern of air-holes, and layer numbers of air-holes. We have determined the values of mode purity for some of the vector modes with respect to the ratio of the annular radii of the ring core $(\rho)$ and the relative air-hole diameter $(d / \wedge)$ of the proposed RC-PCF. The inner diameter is fixed in Figure 1 for the increment of supported modes, so the outer diameter can change for determining mode purity. We also varied the relative air-hole diameter at the cladding region to evaluate the values of mode purity. It is evaluated through Equation (6).

The graphical representation of OAM purity for some vector modes is shown in Figure 8 with varying structural parameters. Here, two cases are presented with three phases for each case. Firstly, the annular radii of ring-core $(\rho)$ are fixed at 0.71 and the relative air diameter $(\mathrm{d} / \wedge)$ is varied at $0.83,0.78$, and 0.73 . Then, the relative air diameter $(\mathrm{d} / \wedge)$ is fixed at 0.83 and the annular radii of the ring-core $(\rho)$ are varied at $0.68,0.65$, and 0.62. In these two cases, the values of $\rho$ and $d / \wedge$ are fixed at 0.71 and 0.83 , respectively, in two cases, because these values are fixed at the proposed PCF for analyzing the other parameters of the OAM transmission. In Figure 8, it is plainly shown that the values of OAM purity vary from 0.9320 to 0.9599 . This high value of OAM purity ensures the robust transmission of optical communication. All the above-discussed parameters with numerical values are summarized in Table 3. 


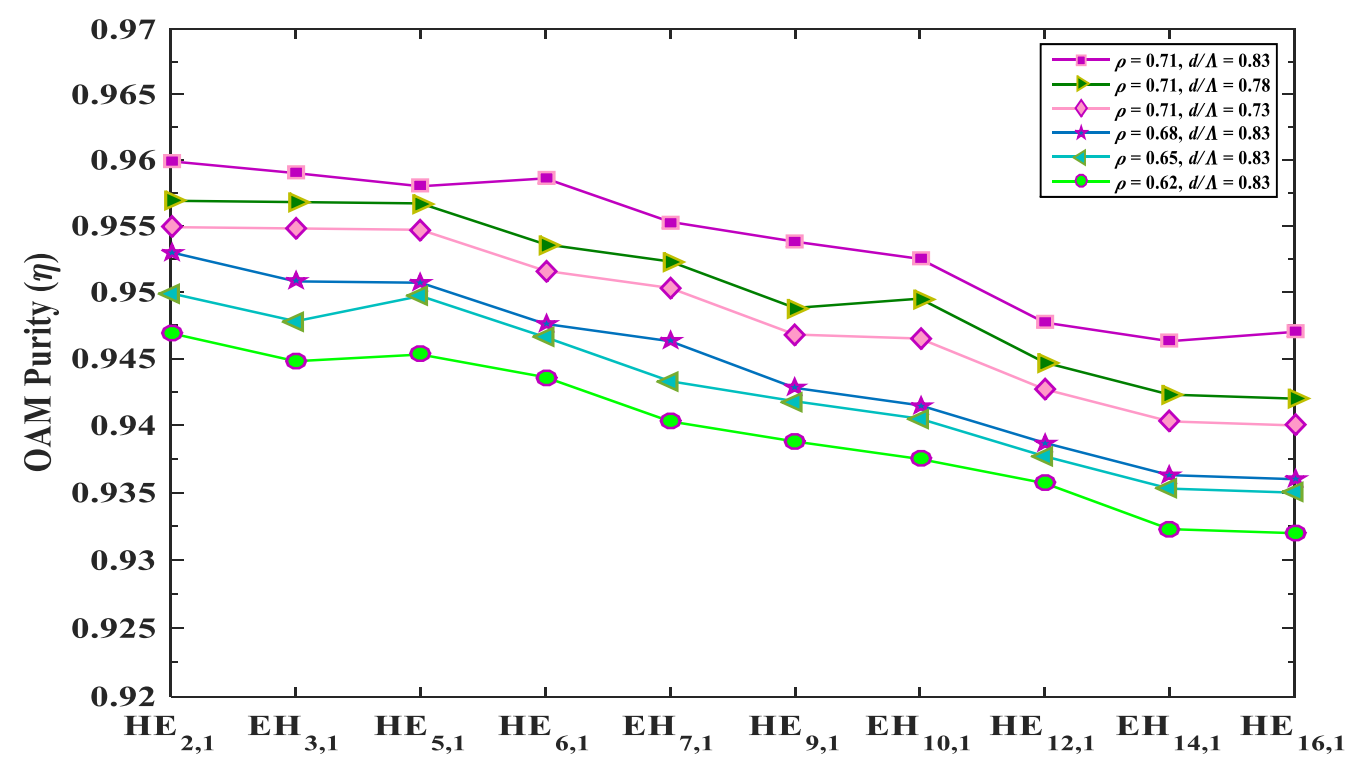

Figure 8. OAM purity for some leading vector modes by changing the ratio of annular radii of the ring-core and the relative air diameter.

Table 3. Summary of key parameters for the proposed RC-PCF.

\begin{tabular}{cc}
\hline Key Parameters & Numerical Values \\
\hline Number of Supported OAM modes & 58 \\
Operating Bandwidth & $0.20-0.90 \mathrm{THz}$ \\
Effective refractive index difference & $>10^{-4}$ \\
Dispersion & $0.23-7.77 \mathrm{ps} / \mathrm{THz} / \mathrm{cm}$ \\
Confinement Loss & $6.91 \times 10^{-9}-8.21 \times 10^{-9} \mathrm{~dB} / \mathrm{cm}$ \\
OAM Purity & $0.9320-0.9599$ \\
\hline
\end{tabular}

The simulation results and discussion section show some effective properties for $\mathrm{THz}$ OAM transmissions. Table 2 shows the confinement loss, dispersion variation and number of supported vector modes, which are better than the previously discussed fibers. The summary of Table 3 for the proposed PCF shows fruitful and feasible properties in the first time of $\mathrm{THz}$ OAM transmission with a simple and unique structure of the fiber. A circular design of a micro-structure ring-core fiber is designed and discussed by Huang et al. [43] in 2019. They just discussed some basic wavelength-based parameters of optical communication with the output of relatively high confinement loss and high dispersion. But, in the proposed work, some more special and essential parameters in optical communication are analyzed. Extremely low confinement loss, lower dispersion profile, and high OAM purity are obtained in a more bandwidth ranged $\mathrm{THz}$ domain. The main limitations of the proposed fiber are a limited number of OAM modes and a less concentrated light beam. Thus, it can be disclosed that the submitted PCF in the THz frequency band is the robust candidate for $\mathrm{THz}$ OAM transmissions and high-reliability optical fiber communication.

\section{Fabrication Possibility}

The proposed structure in Figure 1 is a robust candidate for guiding $\mathrm{THz}$ OAM transmissions. The summaries of characteristics for the proposed RC-PCF neatly show that the PCF maintained a better efficiency and ultra-feasible parameters. Thus, we have to discuss the fabrication procedure of this fiber. In Figure 1, it is displayed that in the cladding region there is a layer of air holes with 12 large air holes. The layer of the air hole is symmetrically patterned. A single layer of a circular air-hole can be easy to fabricate. Since the $\mathrm{THz}$ OAM is a new concept in optical communication, the simplicity of a fiber is not a big deal. Besides, the cladding region is doped by the fused silica with a refractive 
index of 1.446. Any kind of fused silica-based PCF structures can be fabricated by using a method-the 'sol-gel' method—which was proposed and analyzed by El et al. [56] in 2012. The proposed fiber has a very simple air holes pattern. Any type of fiber shape can be fabricated and the freedom to organize air-hole size, shape, and spacing are provided through this 'sol-gel' method. Nonetheless, the proposed fiber has a ring-core with a highly refractive index based material-Schott Sulfur Di-fluoride $\left(\mathrm{SF}_{2}\right)$ - with a refractive index of 1.62. This doped area is named the mode-covered ring-core region. The fabrication procedure has become complex for this material doped ring-core. Nowadays, the ringcore-based PCF of OAM transmission is common. Previously, highly indexed doped ring-core-based fibers are proposed and analyzed in References [41-44,57]. A material doped ring-core OAM transmission supported PCF is designed, analyzed and fabricated by C. Brunet et al. [57] in 2014. Consequently, in 2019, a micro-structure ring-core fiber is designed and the fabrication technique is discussed by Huang et al. [43]. The ring-core of this fiber is doped through the high indexed material of Phosphate glass and Schott sulfur di-fluoride with supporting 70 OAM modes. Moreover, the above-mentioned ringcore fibers of Reference [43] are followed by a fabrication method, which is discussed herein step by step. Firstly, the preform of the ring-core PCF is composed through the modified chemical vapor deposition (MCVD) [58] process. Then, they instrumentally and mechanically punched the preform or extrudes the preform through custom dyes to generate the piece of fiber [59]. At last, the preforms are compressed and drawn into the fiber. Then, these are put into a furnace at a suitable temperature. So, the proposed RC-PCF can be fabricated by following these processes. The proposed fiber is advantageous for guiding $\mathrm{THz} \mathrm{OAM}$ with the multi-mode and wide-band transmission.

\section{Conclusions}

In conclusion, a ring-core circular photonic crystal fiber is proposed and analyzed in this paper. The ring core is doped by Schott $S_{2}$ material. This PCF supports 58 OAM modes in a broad THz frequency spectrum from $0.20 \mathrm{THz}$ to $0.90 \mathrm{THz}$. The supported OAM modes of the proposed PCF are well-separated for their unique design and high refractive index difference up to $10^{-4}$. The confinement loss is ultra-low for its ring-core and large air holes. The lowest confinement loss is $6.91 \times 10^{-9} \mathrm{~dB} / \mathrm{cm}$. Moreover, the flat dispersion and smooth dispersion variation are obtained for this PCF. The lowest dispersion variation is $0.8881 \mathrm{ps} / \mathrm{THz} / \mathrm{cm}$. Besides, the supported modes of this fiber are well confined and the highest mode purity is 0.9599 . By developing the manufacturing technique day by day, the proposed PCF can be fabricated successfully and applied in the THz OAM transmission. By evaluating the performances of the proposed fiber, it is a promising candidate for optical communications, especially in the fields of encoding, multiplexing, demultiplexing, sensing, supercontinuum generation, long-haul, and dense-capacity optical fiber transmissions, and other fields of applications.

Author Contributions: The authors contributed equally to this work. All authors have read and agreed to the published version of the manuscript.

Funding: The work is funded by grant number 12-INF2970-10 from the National Science, Technology and Innovation Plan (MAARIFAH), the King Abdul-Aziz City for Science and Technology (KACST), Kingdom of Saudi Arabia. We thank the Science and Technology Unit at Umm Al-Qura University for their continued logistics support.

Data Availability Statement: Samples of the compounds are available from the authors.

Acknowledgments: This manuscript has not been published yet and not even under consideration for publication elsewhere. The authors are grateful who have participated in this research work.

Conflicts of Interest: The authors declare no conflict of interest. 


\section{References}

1. Kan, T.; Kasai, K.; Yoshida, M.; Nakazawa, M. 42.3-Tbit/s, 18-Gbaud 64 QAM WDM coherent transmission of $160 \mathrm{~km}$ over full C-band using an injection locking technique with a spectral efficiency of 9 bit/s/Hz. In Proceedings of the 2017 Optical Fiber Communications Conference and Exhibition (OFC), Los Angeles, CA, USA, 19-23 March 2017; Volume 25, pp. 1-3.

2. Nitta, J.; Yoshida, M.; Kimura, K.; Kasai, K.; Hirooka, T.; Nakazawa, M. Single-channel 3.84 Tbit/s, 64 QAM coherent Nyquist pulse transmission over $150 \mathrm{~km}$ with a spectral efficiency of $10.6 \mathrm{bit} / \mathrm{s} / \mathrm{Hz}$. Opt. Express 2017, 25, 15199-15207. [CrossRef]

3. Schuh, K.; Buchali, F.; Idler, W.; Eriksson, T.A.; Schmalen, L.; Templ, W.; Altenhain, L.; Dümler, U.; Schmid, R.; Möller, M.; et al. Single carrier 1.2 Tbit/s transmission over $300 \mathrm{~km}$ with PM-64 QAM at 100 GBaud. In Optical Fiber Communication Conference; Optical Society of America: Los Angeles, CA, USA, 2017; p. Th5B.5.

4. Richardson, D.J.; Fini, J.M.; Nelson, L.E. Space-division multiplexing in optical fibers. Nat. Photonics 2013, 7, 354. [CrossRef]

5. Cui, X.Z.; Yin, X.L.; Chang, H.; Sun, Z.W.; Wang, Y.J.; Tian, Q.H.; Wu, G.H.; Xin, X.J. Analysis of the orbital angular momentum spectrum for Laguerre-Gaussian beams under moderate-to-strong marine-atmospheric turbulent channels. Opt. Commun. 2018, 426, 471-476. [CrossRef]

6. Wang, J. Advances in communications using optical vortices. Photonics Res. 2016, 4, B14-B28. [CrossRef]

7. Fürhapter, S.; Jesacher, A.; Bernet, S.; Ritsch-Marte, M. Spiral phase contrast imaging in microscopy. Opt. Express 2005, 13, 689-694. [CrossRef]

8. Padgett, M.; Bowman, R. Tweezers with a twist. Nat. Photonics 2011, 5, 343-348. [CrossRef]

9. Erhard, M.; Fickler, R.; Krenn, M.; Zeilinger, A. Twisted photons: new quantum perspectives in high dimensions. Light Sci. Appl. 2018, 7, 17146-17146. [CrossRef]

10. Padgett, M.J. Orbital angular momentum 25 years on. Opt. Express 2017, 25, 11265-11274. [CrossRef]

11. Durnin, J.J.J.M.; Miceli, J.J., Jr.; Eberly, J.H. Diffraction-free beams. Phys. Rev. Lett. 1987, 58, 1499. [CrossRef]

12. Sueda, K.; Miyaji, G.; Miyanaga, N.; Nakatsuka, M. Laguerre-Gaussian beam generated with a multilevel spiral phase plate for highintensity laser pulses. Opt. Express 2004, 12, 3548-3553. [CrossRef]

13. Huang, H.; Milione, G.; Lavery, M.P.; Xie, G.; Ren, Y.; Cao, Y.; Ahmed, N.; Nguyen, T.A.; Nolan, D.A.; Li, M.J.; et al. Mode division multiplexing using an orbital angular momentum mode sorter and MIMO-DSP over a graded-index few-mode optical fiber. Sci. Rep. 2015 5, 1-7. [CrossRef]

14. Yan, Y.; Xie, G.; Lavery, M.P.; Huang, H.; Ahmed, N.; Bao, C.; Ren, Y.; Cao, Y.; Li, L.; Zhao, Z.; et al. High-capacity millimeter-wave communications with orbital angular momentum multiplexing. Nat. Commun. 2014, 5, 1-9. [CrossRef]

15. Li, S.; Wang, J. Compensation of a distorted $\mathrm{N}$-fold orbital angular momentum multicasting link using adaptive optics. Opt. Lett. 2016, 41, 1482-1485. [CrossRef]

16. Ramachandran, S.; Gregg, P.; Kristensen, P.; Golowich, S.E. On the scalability of ring fiber designs for OAM multiplexing. Opt. Express 2015, 23, 3721-3730. [CrossRef] [PubMed]

17. Brunet, C.; Ung, B.; Wang, L.; Messaddeq, Y.; LaRochelle, S.; Rusch, L.A. Design of a family of ring-core fibers for OAM transmission studies. Opt. Express 2015, 23, 10553-10563. [CrossRef]

18. Ye, J.; Li, Y.; Han, Y.; Deng, D.; Guo, Z.; Gao, J.; Sun, Q.; Liu, Y.; Qu, S. Excitation and separation of vortex modes in the twisted air-core fiber. Opt. Express 2016, 24, 8310-8316. [CrossRef]

19. Zhang, Z.; Gan, J.; Heng, X.; Wu, Y.; Li, Q.; Qian, Q.; Chen, D.; Yang, Z. Optical fiber design with orbital angular momentum light purity higher than 99.9\%. Opt. Express 2015, 23, 29331-29341. [CrossRef] [PubMed]

20. Yan, Y.; Wang, J.; Zhang, L.; Yang, J.Y.; Fazal, I.M.; Ahmed, N.; Shamee, B.; Willner, A.E.; Birnbaum, K.; Dolinar, S. Fiber coupler for generating orbital angular momentum modes. Opt. Lett. 2011, 36, 4269-4271. [CrossRef] [PubMed]

21. Li, H.; Ren, G.; Zhu, B.; Gao, Y.; Yin, B.; Wang, J.; Jian, S. Guiding terahertz orbital angular momentum beams in multimode Kagome hollow-core fibers. Opt. Lett. 2017 42, 179-182. [CrossRef]

22. Yao, A.M.; Padgett, M.J. Orbital angular momentum: origins, behavior, and applications. Adv. Opt. Photonics 2011, 3, 161-204. [CrossRef]

23. Xie, Z.; Wang, X.; Ye, J.; Feng, S.; Sun, W.; Akalin, T.; Zhang, Y. Spatial terahertz modulator. Sci. Rep. 2013, 3, 3347. [CrossRef]

24. Liu, C.; Wei, X.; Niu, L.; Wang, K.; Yang, Z.; Liu, J. Discrimination of orbital angular momentum modes of the terahertz vortex beam using a diffractive mode transformer. Opt. Express 2016, 24, 12534-12541. [CrossRef]

25. He, J.; Wang, X.; Hu, D.; Ye, J.; Feng, S.; Kan, Q.; Zhang, Y. Generation and evolution of the terahertz vortex beam. Opt. Express 2013, 21, 20230-20239. [CrossRef] [PubMed]

26. Imai, R.; Kanda, N.; Higuchi, T.; Konishi, K.; Kuwata-Gonokami, M. Generation of broadband terahertz vortex beams. Opt. Lett. 2014, 39, 3714-3717. [CrossRef]

27. Ramachandran, S.; Kristensen, P. Optical vortices in fiber. Nanophotonics 2013, 2, 455-474. [CrossRef]

28. Atakaramians, S.; Afshar, S.; Monro, T.M.; Abbott, D. Terahertz dielectric waveguides. Adv. Opt. Photonics $2013,5,169-215$. [CrossRef]

29. Li, H.; Atakaramians, S.; Lwin, R.; Tang, X.; Yu, Z.; Argyros, A.; Kuhlmey, B.T. Flexible single-mode hollow-core terahertz fiber with metamaterial cladding. Optica 2016, 3, 941-947. [CrossRef] 
30. Navarro-Cía, M.; Melzer, J.E.; Harrington, J.A.; Mitrofanov, O. Silver-coated Teflon tubes for waveguiding at 1-2 THz. J. Infrared Millim. Terahertz Waves 2015, 36, 542-555. [CrossRef]

31. Litchinitser, N.M.; Abeeluck, A.K.; Headley, C.; Eggleton, B.J. Antiresonant reflecting photonic crystal optical waveguides. Opt. Lett. 2002 27, 1592-1594. [CrossRef]

32. Lu, W.; Lou, S.; Argyros, A. Investigation of flexible low-loss hollow-core fibres with tube-lattice cladding for terahertz radiation. IEEE J. Sel. Top. Quantum Electron. 2015, 22, 214-220. [CrossRef]

33. Anthony, J.; Leonhardt, R.; Leon-Saval, S.G.; Argyros, A. THz propagation in kagome hollow-core microstructured fibers. Opt. Express 2011, 19, 18470-18478. [CrossRef]

34. Lai, C.H.; Hsueh, Y.C.; Chen, H.W.; Huang, Y.J.; Chang, H.C.; Sun, C.K. Low-index terahertz pipe waveguides. Opt. Lett. 2009, 34, 3457-3459. [CrossRef]

35. Yang, J.; Zhao, J.; Gong, C.; Tian, H.; Sun, L.; Chen, P.; Lin, L.; Liu, W. 3D printed low-loss THz waveguide based on Kagome photonic crystal structure. Opt. Express 2016, 24, 22454-22460. [CrossRef]

36. Hasan, M.R.; Anower, M.S.; Islam, M.A.; Razzak, S.M.A. Polarization-maintaining low-loss porous-core spiral photonic crystal fiber for terahertz wave guidance. Appl. Opt. 2016, 55, 4145-4152. [CrossRef]

37. Nandam, A.; Shin, W. Spiral photonic crystal fiber structure for supporting orbital angular momentum modes. Optik 2018, 169, 361-367. [CrossRef]

38. Zhang, H.; Zhang, X.; Li, H.; Deng, Y.; Zhang, X.; Xi, L.; Tang, X.; Zhang, W. A design strategy of the circular photonic crystal fiber supporting good quality orbital angular momentum mode transmission. Opt. Commun. 2017, 397, 59-66. [CrossRef]

39. Hassan, M.M.; Kabir, M.A.; Hossain, M.N.; Biswas, B.; Paul, B.K.; Ahmed, K. Photonic crystal fiber for robust orbital angular momentum transmission: design and investigation. Opt. Quantum Electron. 2020, 52, 8. [CrossRef]

40. Kim, M.; Kim, S. Photonic Quasi-crystal Fiber for Orbital Angular Momentum Modes with Ultra-flat Dispersion. Curr. Opt. Photonics 2019, 3, 298-303.

41. Zhang, H.; Han, D.; Xi, L.; Zhang, Z.; Zhang, X.; Li, H.; Zhang, W. Two-layer erbium-doped air-core circular photonic crystal fiber amplifier for orbital angular momentum mode division multiplexing system. Crystals 2019, 9, 156. [CrossRef]

42. Israk, M.F.; Razzak, M.A.; Ahmed, K.; Hassan, M.M.; Kabir, M.A.; Hossain, M.N.; Paul, B.K.; Dhasarathan, V. Ring-based coil structure photonic crystal fiber for transmission of Orbital Angular Momentum with large bandwidth: Outline, investigation and analysis. Opt. Commun. 2020, 473, 126003. [CrossRef]

43. Huang, S.H.; Ma, Q.C.; Chen, W.C.; Liu, H.Z.; Xing, X.B.; Cui, H.; Luo, Z.C.; Xu, W.C.; Luo, A.P. Microstructure ring fiber for supporting higher-order orbital angular momentum modes with flattened dispersion in broad waveband. Appl. Phys. B 2019, 125, 197. [CrossRef]

44. Wang, W.; Wang, N.; Li, K.; Geng, Z.; Jia, H. A novel dual guided modes regions photonic crystal fiber with low crosstalk supporting 56 OAM modes and 4 LP modes. Opt. Fiber Technol. 2020, 57, 102213. [CrossRef]

45. Monfared, Y.E.; Mojtahedinia, A.; Javan, A.M.; Kashani, A.M. Highly nonlinear enhanced-core photonic crystal fiber with low dispersion for wavelength conversion based on four-wave mixing. Front. Optoelectron. 2013, 6, 297-302. [CrossRef]

46. COMSOL AB. Comsol Multiphysics ${ }^{\circledR}$ v. 5.4 www.comsol.com; COMSOL AB: Stockholm, Sweden, 2018.

47. Bjarklev, A. Microdeformation losses of single-mode fibers with step-index profiles. J. Light. Technol. 1986, 4, 341-346. [CrossRef]

48. Zhou, G.; Zhou, G.; Chen, C.; Xu, M.; Xia, C.; Hou, Z. Design and analysis of a microstructure ring fiber for orbital angular momentum transmission. IEEE Photonics J. 2016, 8, 1-12. [CrossRef]

49. Kabir, M.A.; Hassan, M.M.; Hossain, M.N.; Paul, B.K.; Ahmed, K. Design and performance evaluation of photonic crystal fibers of supporting orbital angular momentum states in optical transmission. Opt. Commun. 2020, 467, 125731. [CrossRef]

50. Islam, M.S.; Sultana, J.; Ahmed, K.; Islam, M.R.; Dinovitser, A.; Ng, B.W.H.; Abbott, D. A novel approach for spectroscopic chemical identification using photonic crystal fiber in the terahertz regime. IEEE Sens. J. 2017, 18, 575-582. [CrossRef]

51. Islam, M.; Hossain, M.A.; Haque, F. A Comparative Analysis between Low Loss Kagome Structured THz Hollow Core and Porous Core PCF. AIUB J. Sci. Eng. 2017, 16, 95-100.

52. Xu, M.; Zhou, G.; Chen, C.; Zhou, G.; Sheng, Z.; Hou, Z.; Xia, C. A novel microstructured fiber for OAM mode and LP mode simultaneous transmission. J. Opt. 2018, 47, 428-436. [CrossRef]

53. Zhang, H.; Zhang, W.; Xi, L.; Tang, X.; Zhang, X.; Zhang, X. A new type circular photonic crystal fiber for orbital angular momentum mode transmission. IEEE Photonics Technol. Lett. 2016, 28, 1426-1429. [CrossRef]

54. Kabir, M.A.; Hassan, M.M.; Ahmed, K.; Rajan, M.M.; Aly, A.H.; Hossain, M.N.; Paul, B.K. Novel spider web photonic crystal fiber for robust mode transmission applications with supporting orbital angular momentum transmission property. Opt. Quantum Electron. 2020, 52, 1-17. [CrossRef]

55. Hassan, M.M.; Kabir, M.A.; Hossain, M.N.; Nguyen, T.K.; Paul, B.K.; Ahmed, K.; Dhasarathan, V. Numerical analysis of circular core shaped photonic crystal fiber for orbital angular momentum with efficient transmission. Appl. Phys. B 2020, 126, 1-8. [CrossRef]

56. El Hamzaoui, H.; Ouerdane, Y.; Bigot, L.; Bouwmans, G.; Capoen, B.; Boukenter, A.; Girard, S.; Bouazaoui, M. Sol-gel derived ionic copper-doped microstructured optical fiber: A potential selective ultraviolet radiation dosimeter. Opt. Express 2012, 20, 29751-29760. [CrossRef] [PubMed]

57. Tandjè, A.; Yammine, J.; Dossou, M.; Bouwmans, G.; Baudelle, K.; Vianou, A.; Andresen, E.R.; Bigot, L. Ring-core photonic crystal fiber for propagation of OAM modes. Opt. Lett. 2019, 44, 1611-1614. [CrossRef] [PubMed] 
58. Brunet, C.; Vaity, P.; Messaddeq, Y.; LaRochelle, S.; Rusch, L.A. Design, fabrication and validation of an OAM fiber supporting 36 states. Opt. Express 2014, 22, 26117-26127. [CrossRef]

59. Kumar, V.R.K.; George, A.K.; Reeves, W.H.; Knight, J.C.; Russell, P.S.J.; Omenetto, F.G.; Taylor, A.J. Extruded soft glass photonic crystal fiber for ultra-broad supercontinuum generation. Opt. Express 2002, 10, 1520-1525. [CrossRef] 